\title{
Predicting recurrence of non-small cell lung cancer based on mean computed tomography value
}

\author{
Masaya Tamura*, Isao Matsumoto, Yusuke Tanaka, Daisuke Saito, Shuhei Yoshida and Munehisa Takata
}

\begin{abstract}
Background: The aim of this study was to assess the ability of using mean computed tomography (mCT) values to predict non-small cell lung cancer (NSCLC) tumor recurrence.

Methods: A retrospective study was conducted on 494 patients with stage IA NSCLC. Receiver operating characteristics analysis was used to assess the ability to use $\mathrm{mCT}$ value, $\mathrm{C} / \mathrm{T}$ ratio, tumor size, and SUV to predict tumor recurrence. Multiple logistic regression analyses were performed to determine the independent variables for the prediction of tumor recurrence.

Results: The $\mathrm{m}-\mathrm{CT}$ values were $-213.7 \pm 10.2$ Hounsfield Units (HU) for the recurrence group and $-594.1 \pm 11.6 \mathrm{HU}$ for the non-recurrence group $(p<0.0001)$. Recurrence occurred in 45 patients $(9.1 \%)$. The tumor recurrence group was strongly associated with a high CT attenuation value, high C/T ratio, large solid tumor size, and SUV. The diagnostic value of $\mathrm{mCT}$ value was more accurate than the $\mathrm{C} / \mathrm{T}$ ratio, excluding the pure ground-glass opacity and pure solid $(0<C / T$ ratio $<100)$ groups. The SUV and $\mathrm{mCT}$ are independent predictive factors of tumor recurrence.

Conclusions: The evaluation of $\mathrm{mCT}$ values was useful for predicting recurrence after the limited resection of smallsized NSCLC, and may potentially contribute to the selection of suitable treatment strategies.
\end{abstract}

Keywords: Ground-glass opacity, Mean- computed tomography value, Recurrence free survival

\section{Background}

Ground-glass-opacity (GGO) is defined as a shadow that is completely occupied by a hazy area of increased attenuation in the lung with preserved bronchial and vascular lesion margins when assessed using high resolution computed tomography (HRCT) [1]. Controversy still remains as to the indication of surgical resection or operative procedure for GGO lesions.

It was recently reported that a limited pulmonary resection (wedge resection or segmentectomy) was not inferior to a lobectomy in the management of peripheral small-sized (tumor size $\leq 20 \mathrm{~mm}$ ) adenocarcinoma of the

\footnotetext{
* Correspondence: masatamu2007@yahoo.co.jp

Department of Thoracic Surgery, Kanazawa University School of Medicine, Takara-machi 13-1, Kanazawa 920-8640, Japan
}

lung. The results of the only randomized controlled trial comparing lobectomy with sublobar resection for tumors $<3 \mathrm{~cm}$ showed that in comparison to a lobectomy, limited resection was associated with a $75 \%$ increase in recurrence rates and a 50\% increase in deaths from cancer [2]. Matsumura et al. [3] reported both early and late recurrence after intentional limited resection for cT1aNOM0 non-small cell lung cancer (NSCLC), and reported that of the 21 late recurrence patients, 17(81\%) had tumors with a consolidation/tumor ratio (CTR) > 0.25 .

Patients with GGO-dominant small lung cancer are believed to have a good prognosis $[4,5]$. However, there is no standard method for measuring the area of GGO, and it is not always possible to evaluate the proportion

C C The Author(s). 2021 Open Access This article is licensed under a Creative Commons Attribution 4.0 International License, which permits use, sharing, adaptation, distribution and reproduction in any medium or format, as long as you give appropriate credit to the original author(s) and the source, provide a link to the Creative Commons licence, and indicate if changes were made. The images or other third party material in this article are included in the article's Creative Commons licence, unless indicated otherwise in a credit line to the material. If material is not included in the article's Creative Commons licence and your intended use is not permitted by statutory regulation or exceeds the permitted use, you will need to obtain permission directly from the copyright holder. To view a copy of this licence, visit http://creativecommons.org/licenses/by/4.0/ The Creative Commons Public Domain Dedication waiver (http://creativecommons.org/publicdomain/zero/1.0/) applies to the data made available in this article, unless otherwise stated in a credit line to the data. 
of the solid area in the presence of mixed GGO lesions [6]. Quantitative densitometric methodologies, and mean CT (mCT) number have been reportedly used to evaluate GGO lesions [7-10]. We previously reported that the $\mathrm{mCT}$ value of GGO lesions is a risk factor associated with their future change [11], and the evaluation of $\mathrm{mCT}$ values is useful in predicting less invasive lung cancer [12]. There have been no studies regarding the use of $\mathrm{mCT}$ values in lung cancer and recurrence, which can be of great significance for treatment decisions.

The objectives of this study were to investigate the usefulness of using $\mathrm{mCT}$ values for predicting recurrence, and to assess whether they contribute to determining the benefits of performing a limited resection.

\section{Patients and methods}

\section{Patients}

This study was approved by our hospital's internal review board (2019-137, 3180). Between August 2006 and December 2015, 1413 consecutive patients underwent pulmonary resection for lung cancer.

From these patients, those diagnosed with clinical stage IA lung cancer with a peripherally located tumor were reviewed retrospectively. Lesions with the following criteria were included in this study: radiologically suspicious lung cancer, no sign of nodal involvement, maximum tumor diameter is $\leq 2 \mathrm{~cm}$, or $>2 \mathrm{~cm}, \leq 3 \mathrm{~cm}$ and $\mathrm{C} /$ $\mathrm{T}$ ratio $\leq 0.5$. Patients who received preoperative treatment, such as radiotherapy or chemotherapy, or had multiple lung cancers were excluded from the study.

A total of 494 patients met both clinical and imaging criteria for inclusion in this study. Of these, 228 were men and 266 were women. Their ages ranged from 19 to 91 years, with a median of 66 years. We reviewed their medical records, including the results of pathologic examination and recurrence status. For each case, the surgical specimens were reviewed and classified according to the latest 2015 WHO classification criteria for lung adenocarcinoma as AAH, AIS, and MIA [13].

\section{Patient follow-up and outcomes}

The median follow-up time frame of patients was 55 months (mean: 58.5; 24-150 months). Routine follow-up included a physical examination, chest $\mathrm{CT}$ scan, and blood test every 3-6 months for the first 3 years after surgery and every 6-12 months thereafter. Magnetic resonance imaging and 18F-fluorodeoxyglucose positron emission tomography were also performed as necessary. The primary endpoint was recurrence-free survival, measured from the date of the initial surgical resection to the first evidence of tumor recurrence. Recurrence was diagnosed by physical examination and diagnostic imaging of the lesions. Diagnosis was also histologically confirmed when clinically feasible. Second primary tumors were defined using all available radiologic and pathologic information according to a modified version of the criteria of Martini and Meland [14]. We defined them as a new pulmonary malignancy occurring in a different lobe or lung than the first tumor with no intervening lymph nodes and no evidence of metastases, different histology or subtype and/or molecular genomic differences.

\section{Image acquisition and analysis}

CT scans were performed from lung apex to base at mid-inspiration during a held breath using a section thickness of 1.25 or $2.5 \mathrm{~mm}$ (Asteion 4, Toshiba, Tokyo, Japan). Two radiologists with 20 and 15 years of experience independently viewed these images and subjectively classified the nodules. Pure GGO was defined as a shadow that was completely occupied by a hazy area of increased attenuation of the lung, with preserved bronchial and vascular margins of the lesion with no solid regions on HRCT. The longest diameters of the GGO lesions and solid portion were measured. The proportion of GGO was calculated using a previously published method [15] and defined as the $\mathrm{C} / \mathrm{T}$ ratio. The maximum diameter and one-dimensional $\mathrm{mCT}$ values were measured using a computer graphics support system (Synapse ${ }^{\circ}$ PACS, Fujifilm, Tokyo, Japan). The shape of the region of interest was standardized for each patient and configured by freehand drawing. The $\mathrm{mCT}$ value was evaluated in slice having highest density. The multiobserver variation was corrected by calculating the mean value from the two observers.

\section{Statistical analysis}

Receiver operating characteristics (ROC) analysis was used to compare the ability to predict the recurrence of the lung cancer using the $\mathrm{mCT}$ value, SUV value, $\mathrm{C} / \mathrm{T}$ ratio, solid tumor size, and carcinoembryonic antigen (CEA) cancer blood test value. Univariate and multivariate analysis were carried out to investigate potential pretreatment predictors of recurrence. Univariate and multivariate Cox proportional hazard regression analyses were conducted to evaluate the associations between clinical and imaging metrics with clinical outcome. The 95\% confidence interval (95\% CI) was calculated and all $p$-values were two-sided. Gender, age, type of resection, tumor size, CEA value, SUV, C/T ratio, $\mathrm{mCT}$ value, solid tumor size were all included in the univariate analysis. Since this was a retrospective study, the variables for univariate analysis were selected postoperatively. Variables that can be assessed from medical records, radiologic imaging, nuclear medicine examination, and blood tests that are useful for diagnosing malignant potential were included in the univariate analysis. Univariate factors with a $p$-value of $<0.05$ were included in the 
multivariate analysis. All data regarding continuous variables were expressed as mean \pm SD. Significant differences were assessed using the $t$-test for continuous variables and the chi-square -test for categorical variables. Analyses were performed using the SAS software package (SAS Institute, Inc., Cary, NC). A $p$-value of $<$ 0.05 was considered statistically significant.

\section{Results}

The CT findings of typical GGO lesions are presented in the Fig. 1 and detailed explanation were described in the results section of the report already published 12 . The $\mathrm{mCT}$ values were $-213.7 \pm 10.2 \mathrm{HU}$ for the recurrence group and $-594.1 \pm 11.6 \mathrm{HU}$ for the non-recurrence group $(p<0.0001)$. Clinical and pathological characteristics are shown in Table 1 . During the study period, recurrence occurred in 45 patients (9.1\%): 3 (6.7\%) were stump recurrence, 9 (20\%) were in a different lung lobe, 8 $(17.8 \%)$ were in a lymph node, $6(13.3 \%)$ were dissemination, and 19 (42.2\%) were distant metastasis. Thirty-one (68.9\%) out of 45 cases were diagnosed histologically. Fourteen cases were diagnosed by CT guided biopsy, 9 cases were surgery and 8 were by TBLB or TBNA.

The comparison of clinico-radiological data between lesions in recurrence and non-recurrence are summarized in Table 2 . The recurrence group was strongly associated with a high $\mathrm{mCT}$ value, high $\mathrm{C} / \mathrm{T}$ ratio, large solid tumor size, and high SUV. Age, CEA, SUV, C/T ratio, solid tumor size, and $\mathrm{mCT}$ value were selected factors for the multivariate analysis based on a $p$-value cutoff and possibly based on recognized clinical parameters. We attempted to predict which cancer would recur based on the $\mathrm{mCT}$ value, SUV, C/T ratio, solid tumor size, and CEA, and ROC curve analysis was performed to determine the appropriate cutoff value (Fig. 1). The maximum sensitivity and specificity were obtained at a cutoff value of $-506 \mathrm{HU}, 2.5,38.2 \%, 0 \mathrm{~mm}$, and 5.0 , respectively. The ROC area under the curve value of the mCT value was the highest (0.892; 95\% CI: 0.79-0.91), followed by SUV (0.864; 95\% CI: 0.76-0.88), C/T ratio (0.848; 95\% CI: $0.79-0.86)$, solid tumor size $(0.802$, $95 \%$ CI: 0.69-0.84), and CEA (0.763, 95\% CI: 0.71-0.82). In the patients with non-adenocarcinoma and the pure solid group, the diagnostic value of $\mathrm{mCT}$ value or SUV was poorer compared to that of the adenocarcinoma group. The diagnostic value of $\mathrm{mCT}$ value was superior to the $\mathrm{C} / \mathrm{T}$ ratio, excluding the pure $\mathrm{GGO}$ and pure solid (i.e. $0<\mathrm{C} / \mathrm{T}$ ratio $<100$ ) groups (Table 3 ). Table 4 shows the results of univariate and multivariate analyses for predicting tumor recurrence. Multiple logistic regression analyses using the preoperatively determined variables revealed that SUV $(p=0.041)$ and $\mathrm{mCT}$ values $(p=$ $0.029)$ are independent predictive factors of recurrence. However, the $\mathrm{C} / \mathrm{T}$ ratio was not significant $(p=0.19)$.

\section{Discussion}

The present study aimed to identify the risk factors associated with tumor recurrence after limited resection for

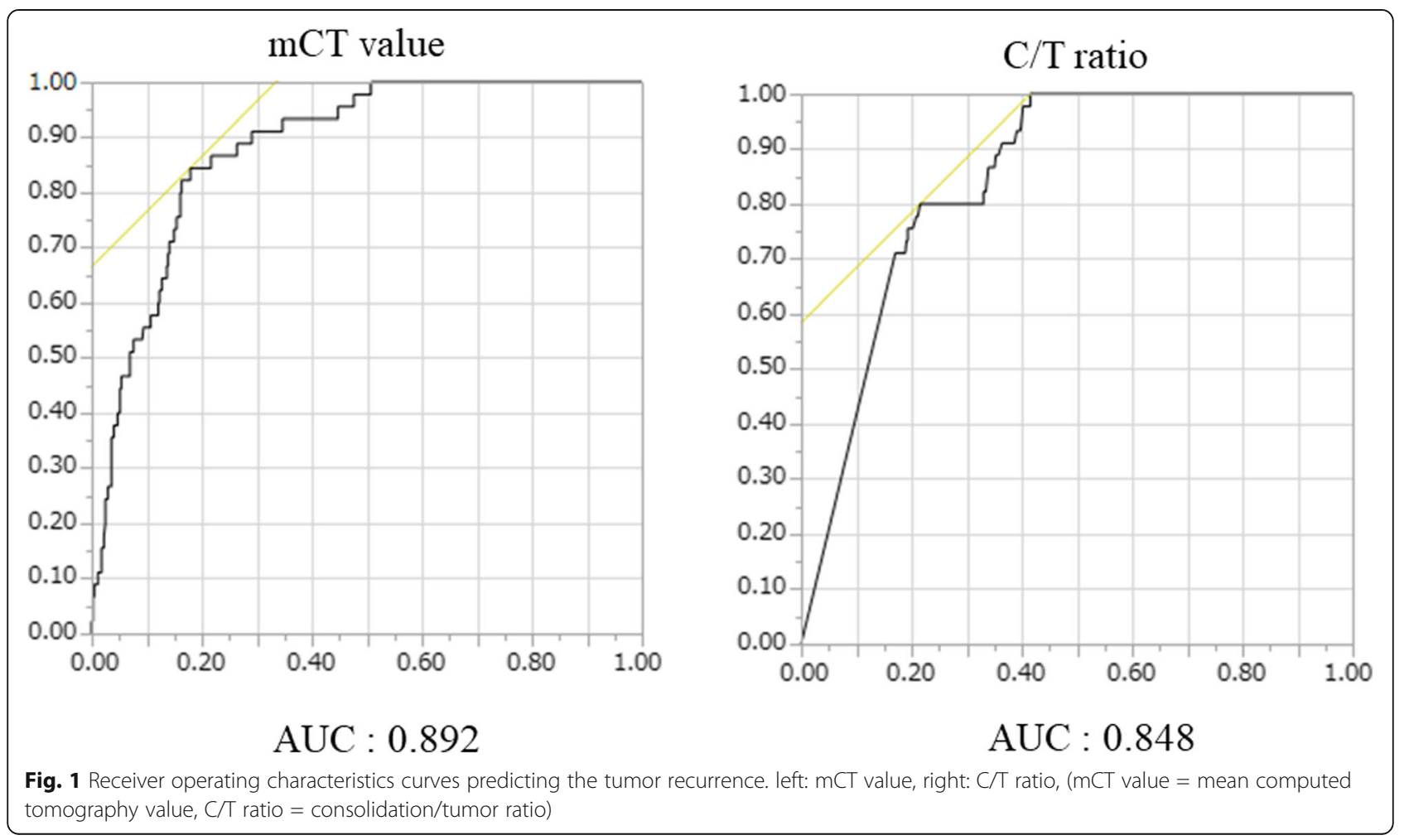


Table 1 Clinical and pathological characteristics

\begin{tabular}{|c|c|c|}
\hline Factors & Number & $\%$ \\
\hline \multicolumn{3}{|l|}{ Gender } \\
\hline Male & 228 & 46.2 \\
\hline Female & 266 & 53.8 \\
\hline \multicolumn{3}{|l|}{ Age } \\
\hline Range & $19-91$ & \\
\hline Mean $\pm S D$ & $65.3 \pm 11.3$ & \\
\hline \multicolumn{3}{|l|}{ Clinical T stage } \\
\hline Tis & 217 & 43.9 \\
\hline T1mi & 57 & 11.5 \\
\hline T1a & 83 & 16.8 \\
\hline T1b & 137 & 27.8 \\
\hline \multicolumn{3}{|l|}{ IASLC } \\
\hline $\mathrm{AAH}$ & 7 & 1.4 \\
\hline AIS & 112 & 22.7 \\
\hline MIA & 208 & 42.1 \\
\hline Invasive adenocarcinoma & 167 & 33.8 \\
\hline \multicolumn{3}{|l|}{ Histology } \\
\hline Adenocarcinoma & 452 & 91.5 \\
\hline Squamous cell carcinoma & 33 & 6.7 \\
\hline Otheors & 9 & 1.8 \\
\hline \multicolumn{3}{|l|}{ Operative procedure } \\
\hline Partial resection & 276 & 55.9 \\
\hline Segmentectomy & 218 & 44.1 \\
\hline
\end{tabular}

IASLC The international association for the study of lung cancer, $A A H$ Atypical adenomatous hyperplasia, AIS Adenocarcinoma in situ, MIA Minimally invasive adenocarcinoma

small-sized NSCLC. Evaluation of various CT features, such as the $\mathrm{mCT}$ values, $\mathrm{C} / \mathrm{T}$ ratio, solid tumor size, whole tumor size, and SUV can be helpful in predicting the potential for tumor recurrence. In particular, we initially demonstrated that the $\mathrm{mCT}$ value of the GGO lesion is a sensitive marker for predicting tumor recurrence.

Although lymphatic or blood vessel invasion is reportedly a strong predictor for postoperative tumor recurrence in completely resected stage I non-small cell carcinoma [16-19], it is difficult to preoperatively identify patients with stage I adenocarcinoma who will have lymphatic or vessel invasion. The preoperative ability to biologically distinguish aggressive tumors from indolent tumors is extremely important for judging whether patients are suitable for sublobar resection. A considerable effort has been exerted to preoperatively distinguish non-invasive versus invasive cancer. In the clinical setting, pathological examination was more important when selecting cases for limited resection. We previously reported that the evaluation of $\mathrm{mCT}$ value is useful in predicting less invasive lung cancer [12]. There have
Table 2 Comparison of clinico-radiological data between lesions in recurrence(+) and recurrence(-) categories

\begin{tabular}{|c|c|c|c|}
\hline Factors & Recurrence(-) (n) & Recurrence(+) (n) & $p$ value \\
\hline Gender & & & $<0.0001$ \\
\hline Male & 195 & 33 & \\
\hline Female & 254 & 12 & \\
\hline Age & & & $<0.0001$ \\
\hline$<65$ years & 207 & 6 & \\
\hline$\geq 65$ years & 242 & 39 & \\
\hline Lesion size & & & $<0.0001$ \\
\hline$<12.9 \mathrm{~mm}$ & 249 & 6 & \\
\hline$\geq 12.9 \mathrm{~mm}$ & 200 & 39 & \\
\hline Histology & & & $<0.0001$ \\
\hline Non adenoca & 29 & 13 & \\
\hline Adenoca & 420 & 32 & \\
\hline mCT value (H.U) & & & $<0.0001$ \\
\hline$<-506$ & 162 & 43 & \\
\hline$\geq-506$ & 287 & 2 & \\
\hline $\mathrm{C} / \mathrm{T}$ ratio & & & $<0.0001$ \\
\hline$<38.2$ & 178 & 39 & \\
\hline$>38.2$ & 271 & 6 & \\
\hline SUV & & & $<0.0001$ \\
\hline$<2.5$ & 426 & 41 & \\
\hline$>2.5$ & 23 & 4 & \\
\hline CEA & & & 0.0022 \\
\hline$<5.0$ & 410 & 27 & \\
\hline$\geq 5.0$ & 39 & 18 & \\
\hline Operative procedure & & & 0.122 \\
\hline Partial resection & 246 & 30 & \\
\hline Segmentectomy & 203 & 15 & \\
\hline Solid tumor size (mm) & & & $<0.0001$ \\
\hline 0 & 217 & 0 & \\
\hline$>0$ & 232 & 45 & \\
\hline
\end{tabular}

$n$ number of cases, non-recurrence (-) without recurrence, recurrence (+) with recurrence, HU Hounsfield unit, CT Computed tomography, C/T ratio Consolidation / tumor ratio, SUV Standardized uptake value, CEA Carcinoembryonic antigen

been no studies regarding the $\mathrm{mCT}$ value in lung cancer and recurrence, which is of great significance for treatment decisions. In the present study, we had selected tumor recurrence as the endpoint.

With recent advances in diagnostic imaging technologies, GGO lesions are increasingly detected using HRCT scans $[20,21]$. GGO is defined as a shadow that is completely occupied by a hazy area of increased attenuation in the lung with preserved bronchial and vascular lesion margins when assessed using HRCT [1]. In a clinical setting, several types of GGO can be encountered. It is difficult to measure the size of the solid part of the tumor 
Table 3 Comparison of AUC between $m-C T$ value, SUV value, $C / T$ ratio and CEA

\begin{tabular}{llllll}
\hline Factors & Total & Adeno & Non-adeno & Pure solid & $\mathbf{0}$ CT ratio $<100$ \\
\hline mean CT value & 0.892 & 0.879 & 0.791 & 0.662 & 0.762 \\
SUV value & 0.864 & 0.884 & 0.55 & 0.607 & 0.847 \\
C/T ratio & 0.848 & 0.856 & - & - & 0.571 \\
CEA & 0.763 & 0.771 & 0.47 & 0.532 & 0.512 \\
\hline
\end{tabular}

CT Computed tomography, SUV Standardized uptake value, $C / T$ ratio Consolidation / tumor ratio, CEA Carcinoembryonic antigen

when the nodule comprises a heterogeneous mixture of GGO and solid tumor. Suzuki et al. [6] classified peripheral small-sized adenocarcinoma into six categories, and reported that the classification was significantly associated with pathologic prognostic factors.

Several authors have classified small lung lesions into nonsolid (pure) GGO, partly solid (mixed) GGO, and solid types. However, it is sometimes difficult to differentiate between pure and mixed GGO, and between high-density GGO and solid tumors, because no definite radiological criteria exist to distinguish these differences. Some authors used quantitative densitometric methodologies to evaluate GGO lesions [11, 19-21]. Although the one-dimensional quantitative $\mathrm{mCT}$ value can be slightly affected by the densities of vessels or bronchi within the tumor, this calculation method is straightforward, and can similarly estimate pure GGO and mixed GGO.
Our study indicated that the predictive ability of the $\mathrm{mCT}$ value for tumor recurrence was higher for smallsized tumors and tumors showing extensive GGO. For solid-predominant tumors, SUV demonstrated higher predictive ability than did the $\mathrm{mCT}$ value. The $\mathrm{mCT}$ value is useful for tumors that are mainly homogeneous in density, or those that are too dense to be called pure GGO but are not pure solid tumor. The mCT value adds a diagnostic value to the $\mathrm{C} / \mathrm{T}$ ratio for tumors for which the size of solid portion is difficult to measure. The ROC area under the curve value of the $\mathrm{mCT}$ value was the highest, excluding the pure GGO and pure solid (i.e. $0<$ $\mathrm{C} / \mathrm{T}$ ratio $<100$ ) group (Table 3 ). The GGO legion is commonly seen with adenocarcinomas, while most squamous cell carcinomas or other histology groups show pure solid lesion. That is the reason why the diagnostic power of $\mathrm{mCT}$, SUV, and $\mathrm{C} / \mathrm{T}$ ratio is seen in the adenocarcinoma group.

Table 4 Multiple logistic regression analysis predicting the tumor recurrence

\begin{tabular}{|c|c|c|c|c|c|c|c|c|}
\hline \multirow[b]{2}{*}{ Risk factor } & \multirow[b]{2}{*}{ HR } & \multicolumn{2}{|c|}{ Univariate analysis } & \multirow[b]{2}{*}{$P$-value } & \multirow[b]{2}{*}{ HR } & \multicolumn{3}{|c|}{ Multivariate analysis } \\
\hline & & $95 \% \mathrm{Cl}$ & & & & $95 \% \mathrm{Cl}$ & & $P$-value \\
\hline \multicolumn{9}{|l|}{ Age } \\
\hline $65<$ vs $\leqq 65$ & 1.75 & 1.17 & 2.73 & 0.055 & & & & \\
\hline \multicolumn{9}{|l|}{ Type of resection } \\
\hline PR vs Seg or Lob & 1.31 & 0.944 & 1.81 & 0.11 & & & & \\
\hline \multicolumn{9}{|l|}{ Tumor size } \\
\hline $12.9<\mathrm{vs} \leqq 12.9$ & 2.07 & 1.53 & 2.90 & 0.0001 & 1.28 & 0.91 & 2.21 & 0.26 \\
\hline \multicolumn{9}{|l|}{ CEA } \\
\hline $5.0<\mathrm{vs} \leqq 5.0$ & 1.36 & 0.667 & 2.33 & 0.35 & & & & \\
\hline \multicolumn{9}{|l|}{ SUVmax value } \\
\hline $2.5<\mathrm{vs} \leqq 2.5$ & 2.36 & 1.57 & 3.77 & $<0.0001$ & 2.12 & 1.12 & 2.68 & 0.058 \\
\hline \multicolumn{9}{|l|}{$\mathrm{C} / \mathrm{T}$ ratio } \\
\hline $38.2<v s \leqq 38.2$ & 2.96 & 2.01 & 4.80 & $<0.0001$ & 1.38 & 0.86 & 2.99 & 0.20 \\
\hline \multicolumn{9}{|l|}{ mCT value (H.U) } \\
\hline$\leqq-506$ vs $-506>$ & 3.41 & 2.31 & 5.52 & $<0.0001$ & 2.92 & 1.29 & 11.2 & 0.043 \\
\hline \multicolumn{9}{|l|}{ Solid size } \\
\hline $0<$ vs 0 & 3.93 & 2.59 & 6.68 & $<0.0001$ & 1.49 & 0.78 & 7.12 & 0.11 \\
\hline Ly(-) and $v(-)$ vs others & 3.56 & 2.21 & 4.48 & $<0.0001$ & 3.12 & 1.41 & 5.57 & 0.039 \\
\hline
\end{tabular}

PR Partial resection, Seg Segmentectomy, CEA Carcinoembryonic antigen, SUV Standardized uptake value, C/T ratio Consolidation / tumor ratio, $m C T$ Mean computed tomography, HU Hounsfield unit 
This study has several limitations. First, it was performed retrospectively. Second, the cut-off values of the ROC curves that dichotomized the two groups could be an arbitrary value and not available universally. Fourth, the follow-up duration was rather short, even though the mean interval between the two groups, with and without recurrence, showed no differences $(p=0.52)$.

\section{Conclusions}

In conclusion, $\mathrm{mCT}$ values were useful for predicting recurrence after the limited resection of small-sized NSCL $\mathrm{C}$, in particular, such as patients with adenocarcinoma manifested as mixed GGO, added new information to the $\mathrm{C} / \mathrm{T}$ ratio, and may contribute to selecting suitable treatment strategies. A future prospective study should be conducted to establish the optimal treatment strategies for this disease.

\section{Abbreviations}

AAH: Atypical adenomatous hyperplasia; AIS: Adenocarcinoma in situ; C/T ratio: Consolidation / tumor ratio; DFS: Disease-free survival; GGO: Groundglass opacity; HRCT: High-resolution computed tomography; HU: Housfield units; $\mathrm{m}-\mathrm{CT}$ value: Mean computed tomography value; MIA: Minimally invasive adenocarcinoma; ROC: Receiver operating characteristics; SUV: Standardized uptake value

\section{Acknowledgements}

Not applicable.

\section{Authors'contributions}

YT, DS, SY and MuT analyzed and interpreted the patient data. MaT performed the literature review, and was a major contributor in writing the manuscript. IM performed the final editing of the manuscript. All authors read and approved the final manuscript.

\section{Funding}

Not applicable.

\section{Availability of data and materials \\ Not applicable.}

\section{Declarations}

Ethics approval and consent to participate

This study was approved by our hospital's internal review board (2019-137: 3180).

\section{Consent for publication}

Written informed consent was obtained from the patient for publication of this case report and any accompanying images. A copy of the written consent is available for review by the Editor- in- chief of this journal.

\section{Competing interests}

The authors declare that they have no competing interests.

Received: 13 October 2020 Accepted: 5 April 2021

Published online: 12 May 2021

\section{References}

1. Park CM, Goo JM, Lee HJ, Lee CH, Chun EJ, Im JG. Nodular ground-glass opacity at tin- section CT: histologic correlation and evaluation of change at follow-up. Radiographics. 2007;27(2):391-408. https://doi.org/10.1148/rg.272 065061

2. Ginsberg RJ, Rubinstein LV. Randomized trial of lobectomy versus limited resection for T1N0M0 non-small cell lung cancer. Ann Thorac Surg. 1995; 60(3):615-23. https://doi.org/10.1016/0003-4975(95)00537-U.
3. Matsuura N, Go T, Fujiwara A, Nakano T, Nakashima N, Yokomise H, et al. Lymphatic invasion is a cause of local recurrence after wedge resection of primary lung cancer. Gen Thorac Cardiovasc Surg. 2019;67(10):861-6. https://doi.org/10.1007/s11748-019-01095-6.

4. Kodama K, Higashiyama M, Yokouchi H, Takami K, Kuriyama K, Nakayama T, et al. Prognostic value of ground-glass opacity found in small lung adenocarcinoma on high-resolution CT scanning. Lung Cancer. 2001;33(1): 17-25. https://doi.org/10.1016/S0169-5002(01)00185-4.

5. Asamura H, Hishida T, Suzuki K, Koike T, Nakamura K, Fukuda H, et al. Japan clinical oncology group lung Cancer surgical study group. Radiographically determined noninvasive adenocarcinoma of the lung: survival outcomes of Japan clinical oncology group 0201. J Thorac Cardiovasc Surg. 2013;146(1): 24-30. https://doi.org/10.1016/j.jtcvs.2012.12.047.

6. Suzuki K, Kusumoto M, Watanabe S, Tsuchiya R, Asamura H. Radiologic classification of small adenocarcinoma of the lung: radiologic-pathologic correlation and its prognostic impact. Ann Thorac Surg. 2006;81(2):413-20. https://doi.org/10.1016/j.athoracsur.2005.07.058.

7. Yang ZG, Sone S, Takashima S, Li F, Honda T, Kawakami S, et al. Highresolution $\mathrm{CT}$ analysis of small peripheral lung adenocarcinomas revealed on screening helical CT. Am J Roentogenol. 2001;176(6):1399-407. https:// doi.org/10.2214/ajr.176.6.1761399.

8. Ikeda K, Awai K, Mori T, Kawanaka K, Yamashita Y, Nomori H. Differential diagnosis of ground-glass opacity nodules. CT number analysis by three dimensional computerized quantification. CHEST. 2007;132(3):984-90. https://doi.org/10.1378/chest.07-0793.

9. Nomori H, Ohtsuka T, Naruke T, Suemasu K. Differentiating between atypical adenomatous hyperplasia and bronchioloalveolar carcinoma using the computed tomography number histogram. Ann Thorac Surg. 2003;76(3): 867-71. https://doi.org/10.1016/S0003-4975(03)00729-X.

10. Yanagawa M, Kuriyama K, Kunitomi Y, Tomiyama N, Honda O, Nakamura H, et al. One-dimensional quantitative evaluation of peripheral lung adenocarcinoma with or without ground-glass opacity on thin-section C images using profile curve. Br J Radiol. 2009;82(979):532-40. https://doi. org/10.1259/bjr/70480730.

11. Tamura M, Shimizu Y, Yamamoto T, Yoshikawa J, Hashizume Y. Predictive value of one-demensional mean computed tomography value of ground-glass opacity on high-resolution images for the possibility of future change. J Thorac Oncol. 2014;9(4):469-72. https://doi.org/10.1097/JTO.0000000000000117.

12. Tamura M, Matsumoto I, Saito D, Yoshida S, Kakegawa S, Takemura H. Mean computed tomography value to predict the tumor invasiveness in clinical stage IA lung cancer. Ann Thorac Surg. 2017;104(1):261-6. https://doi.org/1 0.1016/j.athoracsur.2017.01.060.

13. Lee HY, Choi YL, Lee KS, Han J, Zo J, Moon JE, et al. Pure ground-glass opacity neoplastic lung nodules: histopathology, imaging, and management. Am J Roentogenol. 2014;202(3):224-33.

14. Martini N, Melamed MR. Multiple primary lung cancer. J Thorac Cardiovasc Surg. 1975;70(4):606-12.

15. Matsuguma H, Nakahara R, Anraku M, Kondo T, Ysuura Y, Yokoi K, et al. Objective definition and measurement method of ground-glass opacity for planning limited resection in patients with clinical stage IA adenocarcinoma of the lung. Eur J Cardiothorac Surg. 2004;25(6):1102-6. https://doi.org/10.1 016/j.ejcts.2004.02.004

16. Ogawa J, Tsurumi T, Yamada S, Koide A. Shohtu et al. blood vessel invasion and expression of syalyl Lewisx and proliferating cell nuclear antigen in stagelnon-small cell lung cancer. Relation to postoperative recurrence. Cancer. 1994;15(73):1177-83.

17. Ichinose $Y$, Yano T, Yokoyama H, Inoue T, Asoh H, Katsuda T. The correlation between tumor size and lymphatic vessel invasion in resected peripheral stagelnon-small cell lung cancer. A potential risk of limited resection. J Thorac Cardiovasc Surg. 1994;108(4):684-6. https://doi.org/10.1016/S00225223(94)70294-2.

18. Kessler R, Gasser B, Massard G, Roeslin N, Meyer P, Morand G, et al. Blood vessel invasion is a major prognostic factor in resected non-small cell lung cancer. Ann Thorac Surg. 1996;62(5):1489-93. https://doi.org/10.1016/0003-4 975(96)00540-1.

19. Tsuchiya T, Hashizume S, Akamine S, Muraoka M, Honda S, Nagayasu T, et al. Upstaging by vessel invasion improves the pathology staging system of non-small cell lung cancer. CHEST. 2007;132(1):170-7. https:/doi.org/10.1378/chest.06-1950.

20. Sone S, Takashima S, Li F, Yang Z, Honda T, Asakura K, et al. Mass screening for lung cancer with mobile spiral computed tomography scanner. Lancet. 1998;351(9111):1242-5. https://doi.org/10.1016/S0140-6736(97)08229-9. 
21. Sobue T, Moriyama N, Kaneko M, Kusumoto M, Kobayashi T, Eguchi K, et al. Screening for lung cancer with low-dose helical computed tomography: anti-lung cancer association project. J Clin Oncol. 2002;20(4):911-20. https:// doi.org/10.1200/JCO.2002.20.4.911.

\section{Publisher's Note}

Springer Nature remains neutral with regard to jurisdictional claims in published maps and institutional affiliations.

Ready to submit your research? Choose BMC and benefit from:

- fast, convenient online submission

- thorough peer review by experienced researchers in your field

- rapid publication on acceptance

- support for research data, including large and complex data types

- gold Open Access which fosters wider collaboration and increased citations

- maximum visibility for your research: over $100 \mathrm{M}$ website views per year

At $\mathrm{BMC}$, research is always in progress.

Learn more biomedcentral.com/submissions 